\title{
XXXIX. Process for procuring pure platinum, palladium, rhodium, iridium, and osmium, from the ores of platinum
}

\section{Baruel}

To cite this article: M. Baruel (1822) XXXIX. Process for procuring pure platinum, palladium, rhodium, iridium, and osmium, from the ores of platinum , Philosophical Magazine Series 1, 59:287, 171-179, DOI: $10.1080 / 14786442208652713$

To link to this article: http://dx.doi.org/10.1080/14786442208652713

电 Published online: 29 Jul 2009.

Submit your article to this journal $\pi$ 
the act of irhaling the gas, it would pass from the bladder into his lungs, and when he exhaled, the breath would pass through the other tube that has the valve to open outward into the air. Pratten's Row, Lawrence Hill, Bristol, I remain respectfully, \&c. Jan. 10, $1 \times 22$.

XXXIX. Process for procuring pure Platinum, Palladium, Rhodium, Iridium, and Osmium, from the Ores of Platinum. By M. BarUEL, Chemical Operalor in the School of Medicine at Paris*.

1. Two sorts of platinum ore occur in commerce, one of which is white and brilliant, the other is blackish coloured. The latter contains much more iron $\uparrow$ than the preceding ; both ores exist always in the form of small spangles, which vary in size ; platinum ore is one of the most compound known : besides the five metals above noted, several others are found in it, especially two kinds of ferruginous sand, one of them attractible by the magnet, the other not, and which is a combination of the oxides of titanium and iron : there is, besides chromate of iron, some copper, particles of gold alloyed with silver, with copper, and mercury. It contains, moreover, some sulphuret of lead and copper. We may hence judge of the singular complexity of this mineral, and be ready to acknowledge that its exact analysis, in regard to the proportion of its constituents, is nearly impossible. In order to separate the platinum, palladium, rhodium, iridium, and osmium, from each other, and the rest of the bodies, the following method is the one which long experience has proved most successful.

2. The ore is triturated in a cast-iron mortar for a considerable time, during which a stream of water is constantly passed over it, to wash away the ferriferous sand, the titanite, and chromate of iron, reduced to an impalpable powder. When the ore is very brilliant, it is left to settle for an instant; the water is decanted off, and it is then exposed in a crucible to a red heat during a quarter of an hour. The whole mercury is thus volatilized, when we can readily distinguish the spangles of alloy of gold and copper by their colours.

3. The calcined ore being introduced into a tubulated retort, we pour over it half its weight of nitro-muriatic acid (aqua regia)

* From Mr. Brande's Journal of Science. This valuable memoir derives peculiar interest from the large importation of the aiove ore dialy expected from Sopth America, in consequence of the negotiation between $M$. Zea and some London merchants.

+ Rather, the fine black powder, or ore of iridium and osmium, noticcd in paragraph 3.-Tr. 


\section{2 process fur trocuring pure Platinum, Palladizm, \&8c.}

composed of one part of nitric acid at $25^{\circ}$ Baumé $(1 \cdot 210 \mathrm{sp}$. gr. $)$ and three parts of muriatic acid, at $18^{\circ}(1 \cdot 14)$, and heat the mixture for half an hour. Such acid dissolves all the gold, all the lead, the greater part of the copper, and a very small quantity of platinum, palladium, and iron, while the silver is converted into a chloride, which remains mingled with the ore not attacked. After decanting the acid liquor, the ore is thrown on a filter, and washed with a sufficient quantity of water. The filter-funnel being transferred to another vessel, the filter is to be washed with a very weak water of ammonia. By this means we dissulve all the chloride of silver, which is recovered by saturating the filtered liquor with muriatic acil.

4. The solution which contains the gold, lead, copper, and iron, with a small quantity of palladium and platimum, being added to the water which has served for the washings, the whole is now evaporated to the consistence of syrup, which is diluted with thrice its volume of water, and treated with sulphuric acid, drop by drop, to precipitate the lead in the state of sulphate, to be afterwards separated by the filter.

5. Into the filtered liquor a solution of proto-sulphate of iron must be poured, which throws down the gold and palladium in the metallic state. We decant the liquor, wash and dry the precipitated metals. The platinum remains in the liquor with the iron and copper. We concentrate this liquor by evaporation, then pour into it a sufficient quantity of a saturated solution of muriate of ammonia, which throws down the platinum in the state of ammonio-muriate. This must be washed on a filter and dried.

6 . The gold may be very easily separated from the palladium by melting these metals with four times their weight of silver, and acting on the alloy with concentrated nitric acid, which dissolves the palladium and silver, but leaves the gold in the form of a brown powder, which may be fused into a button in a crucible. Into the nitric solution of silver and palladium we pour muriatic acid, which throws down all the silver in the state of chloride. The liquid freed by the filter from the chloride contains only palladium. We add to it a few drops of solution of sal-anmoniac, then saturate the redundant acid by ammonia; the whole palladium is thus precipitated in the state of an ammonia proto-submuriate of palladium, which exhibits small needles, of a delicate rose colour. This salt is to be washed on the filter, and dried.

7. The ore of platinum which has been successively treated with weak nitro-muriatic acid, and then with ammoniacal water, to carry off the chloride of silver, is to be strongly desiccated. Having replaced it in the retort, we pour over it a weight equal to its own of nitro-muriatic acid, made in the same proportion as 
the above, but with this difference, that the acids ought to be as concentrated as possible. I employ for this purpose nitric acid, at $40^{\circ}$ (1.387 sp.gr.) and muriatic acid, at $23 \frac{1}{2} \circ^{\circ}(1.195)$. The retort is placed on a sand-bath, with a tubulated receiver adapted to its neck, and it is heated morlerately. A brisk effervescence soon arises, owing to the disengagement of much nitrous vapour, and a little chlorine. The action of the heat nust be so modified as to produce the most beneficial effect on the solution, withont volatilizing the acid. Finally, when the effervescence ceases, the fire is to be angmented till the liquid boils, and till no more orange nitrous fumes are disengaged.

When the action of the acid is quite exhansted, we decant the liquid into a matrass, and pour on the portion of the ore not attacked the same nitro-muriatic acid, equal in quantity to the first.

The mixture is to be heated anew, observing the same precautions as for the preceding solution. Finally, we treat the ore five times in suceession with the compound acid. By this process six parts of this acid are sufficient to dissolve the whole platinum, palladium, and rhodium contained in the ore.

\$. After the last digestion, which yields only a slightly reddishcoloured solution, there remains a residuum, under the form of a brilliant blackish powder, which consists of an alloy of iridium and osmium. One part of this is a fine powder (see Note to paragraph 1), and the other forms brilliant spangles. We shall return in the sequel to the residuum; let us employ ourselves at present on the solution.

9. We have said that all the platinum, rhodium, and palladium were dissolved; but the acid also dissolves a little iridium and osmium, as well as the iron alloyed with the platinum grains. During the action of the acid on the ore, at the same time that the nitrous gas and chlorine are evolved, there is volatilized a little water and muriatic acid, which carry over with them a notable quantity of oxide of osmium, which is condensed in the receiver.

10. All the successive solutions of the ore of platinum are united and introduced into a retort of proper capacity, to which the receiver containing the former condensed vapours is attached. The retort is now heated on a sand-bath, till its contents acquire the consistence of syrup. By this means we drive off all the excess of the acid, which carries along with it into the receiver the whole oxide of osmium which that solution contained.

11. The product of the last distillation being saturated with lime, we distil over to one-half the volume. 'The product of this new distillation has an extremely penetrating odour, on account 


\section{Process for procuring pure Platinum, Palladium, $\& 5$.}

of the large proportion of oxide of osmium which it contains. It must be preserved in glass bottles, furnished with well-ground stoppers.

12. The concentrated solution of platinum is to be diluted with from five to six'times its weight of water, then filtered.

13. The black powder whieh was not acted on by the nitromuriatic acid, is also to be washed with water, dried, and kept in a phial; we shall distinguish it by the name of the llack powder.

14. Into the filtered solution we pour a saturated solution of muriate of ammonia, till this ceases to occasion any precipitate. In this operation there are formed ammonio-muriates of platinum, irifium, rhodium, and palladium. These two last salts being very soluble, remain in the liquid with the iron; but the ammonio-muriates of platinum and iridium being very sparingly soluble form the precipitate, which has a tawny or reddish-yellow colour of more or less depth, aceording as the proportion of the salt of iridium is more or less considerable. When the further addition of the muriate of ammonia produces no more precipitate, the whole is to be thrown on a filter of cotton, and washed with water of as great coldness as possible, which is conveniently procured by putting a bit of ice into the water intended for the washings. When the precipitate is sufficiently washed, which is recognised by the water that passes having merely a faint yellowish hue, it is to be dried. This precipitate, as we have remarked, is an ammonio-muriate of platimum, the pure yellow of which is altered by its mixture with the ammonio-muriate of iridium, which is red.

15. This impure ammoniacal salt of platinum is calcined in a crueible, observing to heat the crucible at first in its upper part, in order to avoid the volatilization of a portion of the salt, without its being decomposed. The heat is to be pushed to redness, at which temperature it must be kept up for an hour. By this means the salts are decomposed, and there remains in the crucible only the platinum and iridium. To separate these two metals we put them into a retort, and dissolve them anew in the nitro-muriatic acid; but in this case the nitric acid must be only at $28^{\circ}(1 \cdot 24)$, and the muriatic acid at $19^{\circ}(1 \cdot 15)$. Two and a half parts of this acid suffice to dissolve one of platinum thus reduced, without affecting the iridium. This metal remains at the bottom of the liquor (which is of a fine orange-yellow colour) under the form of a grey powder. On filtering, pure iridium remains above, which is to be washed and dried.

16. The solution of platinum must be precipitated once more by muriate of ammonia; and the fine yellow ammonio-muriate 
of platinum thus obtained, is to be reduced by strong calcination in a crucible, observing the precautions already indicated. The pure platinum remains in the crucible, under the form of a greyishcoloured spongy mass, which acquires metallic lustre by friction against any hard body.

17. As platinum can be fused only in small masses at a time, and at a flame supplied with oxygen gas, or the compound flame of oxygen and hydrogen, it cannot be melted on the large scale like most others. However, chemists have succeeded in forming this metal into ingots of a very considerable weight, by uniting the particles with strong pressure at a very high tenperature. For this purpose, a certain quantity of platinum, resulting from the calcination of the triple ammoniacal salt, is compressed in a crucible; then more is successively introduced, even to the amount of 20 or 30 pounds. 'The crucible is then covered, and heated to whiteness. The platinum is now transferred as speedily as possible into a square steel matrix (a strong hoop of steel, jointed, would answer equally well) and capable of opening into two pieces by means of hinges. On the top of the ignited mass, a steel mandril, adapted to the cavity of the matrix, is to be applied, which is to be rapidly driven home, by three or four blows of a strong coining screw-press. By this powerful pressure, which the spongy platinum experiences at a white heat, it diminishes greatly in bulk, and its particles already accuire a pretty strong cohesion. The matrix or collar is opened, the unass of platinum is removed to be heated anew in a crucible to a redwhite heat, at a fire acted on by two good bellows. It is again introduced with the utmost celerity into the matrix, where it receives five or six blows of the fy-press. In the sceond operation, all the particles of the platinum are sufficiently approximaced to form a homogeneous mass, which may be thenceforth heated, without inconvenience, among raked charcual, giving it the greatest possible beat, and condensing, with two blows of the press, each face of the ingot. In thus transferring the mass of platinum successively from the forge to the press about thirty times, we obtain an ingot perfectly sound, possessed of great malleability and ductility. Platinum thus made into ingots, is delivered to the workmen, who fashion it like gold and silver; that is to say, all the pieces are stretched at first under the rolling-press, and then fashioned by the hammer, taking care to anneal it from tiuse to time. Thus are prepared, in France, the great masses of platinum, with which are fabricated the large alembics destined for the concentration of sulphuric acid.

18. The mother-water, from which have been precipitated the ammonio-muriates of platinum and indium by pouring muriate 


\section{Process for procuring pure Platinum, Palladium, $86 \mathrm{c}$.}

of ammonia into the solution of crude platinum, has $n$ reddishbrown colour, and contains all the amnonio-muriates of palladium and rhodium, as well as a certain quantity of the ammoniomuriates of platinum and iridium; because, as we have observed, these salts are not completely insoluble. It contains, moreover, all the iron which was alloyed with the platinum, and sometimes a little copper, which has escaped the action of the first portion of nitro-muriatic acid which was poured on the ore to dissolve the gold. This mother-liquor is put into matrasses, and plates of iron are plunged into it. The iron precipitates all the metals (except the oxide of iron) under the form of a black powder. When the whole metallic matter is thrown down, which is known by the liquor assuming a green colour, the plates of iron are removed, after detaching from their surfaces the adhering powder. The liquor is decanted off, and thrown away. The black precipitate must be washed several times, till the water employed passes off tasteless. The powder is then treated with weak nitric acid, which dissolves the greatest part of the iron, which, by the effect of the precipitation, had been alloyed with these metals*, and which takes up also whatever copper may remain. 'The residuum is washed anew, and treated with nitro-muriatic acid, which dissolves all the platinum, palladium, rhodium, and remains of the iron; but does not affect the iridium, which remains pure at the bottom of the solution in the form of a black powder, or metallic spangles. The iridium, being separated by the flter, is then washed, dried, and united to that formerly obtained (15).

19. The liquors are now to be united, and evaporated to the consistence of syrup, to dive off the greater part of the acid excess; then this is to be diluted with four or five times its weight of water, as cold as possible. Into this a solution of muriate of ammonia is to be poured, till it ceases to occasion a precipitate. What falls is an ammonio-muriate of platinum, which must be separated by filtration. The solution is then concentrated, and allowed to cool several times in stccession, to separate all the ammoniacal salt of platinum which it may contain. When the linuid is completely deprived of platinum, or when it yields no longer the yellow precipitate, we dilute it with fove or six parts of cold water; and it ought to have a sensible excess of acil. This, if wanting, may le supplied by adding a litcle of the muriatic. We then pour into it water of ammonia, drop by drop, but not so much as entirely to saturate the acid-excess. Imme-

* Or, during the precipitution had fallen down in alloy with these metals. The original words are, "fer, qui par l'effet de la précipitation s'étoit allié avec ces métaux." 
diately there is formed, in the liquid, a precipitate in the shape of small needles, delicate and shining, possessing a beantiful pale rose-colour. This crystalline precipitate is an ammonio-subprotomuriate of palladium. Since this salt is insoluble, there can remain none of it in the liquid. It may be separated by the filter, and washed with very cold water. By heating this salt to redness in a crucible, the palladium remains pure. It may be afterwards melted in a cavity of ignited charcoal, on which a stream of oxygen gas is made to play.

20. The liquid freed from the salt of palladium, possesses a fine currant-red colour, derived from the ammonio-muriate of rhodium, which it holds in solution, and which is very soluble. It contains, moreover, a little muriate of iron, and occasionally a little muriate of copper, when this metal has not been entirely dissolved by the first portion of nitro-muriatic acid, which was made to act on the ore, as has been stated above. There are two modes of treating this salt, to obtain pure rhodium. The first consists in evaporating this liquid, at a gentle heat, to dryness; and boiling the residuum several times along with absolute alcohol. The spirit dissolves all the muriate of iron and copper, with the excess of sal-ammoniac, and does not affect the ammonio-muriate of rhodium, which remains in the form of a saline powder of a fine carmine-red colour. By calcining this salt to redness in a crucible, we decompose it, and the rhodium remains pure and perfectly metallic. The second means of obtaining the rhodium from the above liquid, consists in plunging into it plates of iron. The rhodium and the copper are precipitated, carrying down with them a little iron. When every thing is fallen down, the liquor is decanted, the precipitate is washed, and boiled with an excess of strong muriatic acid, which dissolves all the iron. The liquid is now poured off, the residuum is washed with a suffieient quantity of water, and is next boiled several times with concentrated nitric acid, which dissolves all the copper. The rhodium being completely insoluble in each of these acids separately, remains under the form of shining pellicles, which must be washed and dried. Rhodium being the most infusible of metals, cannot be melted but in small pieces, by the aid of a flame fed with oxygen gas, or by the compound flame of hydrogen and oxygen.

21 . Let us return to the black powder separated from the platinum ore, by treating it with nitro-muriatic acid. We have said that this black powler was an alloy of osmium and iridium. It is scarcely affected by any nitro-muriatic acid. It requires, indeed, an enormous quantity of this acid to dissolve a minute particle of it. The only means of attacking this alloy, is to calVol. 59. No. 287. March 1822. 
cine it with nitrate of potash. With this view, we triturate the black powder with twice its weight of a mixture of three parts of nitre and one of caustic potash, and introduce the whole into a silver crucible, which is to be kept at a cherry-red heat for half an hour. In consequence of the affinity of the potash for the oxides of osmium and iridium, the nitric acid of the nitre is decomposed, and oxidizes these metals. 'The crucible is to be withdrawn from the fire, allowed to cool, and cold water is then poured on the materials. This dissolves the potash, the whole oxide of osmium, and a little of the oxide of iridium. The whole being thrown on a filter, the oxide of iridium remains above, which is to be washed and dried.

22. The filtered liquor which contains the combination of potash and oxide of osmium, as well as a little oxide of iridium, is put into a flask, and saturated with nitric acid. The liquid is then put into a retort, to which is fitted a tubulated globe, surroumded with moistened cloths. On distilling, the water which rises in vapour carries with it all the oxide of osmium. When the liquid is two-thirds drawn over, the whole osmium is usually volatilized. The liquid remaining in the retort contains the nitrate of potash, and a trace of iridium. The aqueous solution of osmium is as colourless and limpid as distilled water. It has a strong and peculiar odour, extremely irritating to the nostrils, and which it is dangerous to inhale for any length of time. In order to obtain the osmium from this solution, it is put into a matrass, and we add a little muriatic acid to acidulate it slightly, and then insert a plate of pure zinc. The oxide of osmium is decomposed by the zinc, which is dissolved in the muriatic acid, and the osmium is precipitated to the bottom of the liquor in the form of a blackish-blue powder. When the oxide of osmium is completely decomposed, which may be recognised by the liquid losing its odour, we decant the fluid, pour the powder of osmium on a filter, wash it copionsly with water, dry it, and put it immediately up in a well-stopped phial.

23. The oxide of iridium, proceeding from the calcination of the black powder with nitre and potash, which remained on the filter, is by no means pure. It is a mixture of oxide of iridium, of a certain quantity of the black powder, or alloy of osmium and jridium, which has not bren affected by the nitre, and a little oxide of silver, derived from the crucible. This mixture is to be treated with nitro-muriatic acid, which dissolves only the oxide of iridium, converts the oxide of silver into a chloride, and does not act on the alloy. We next filter and wash. The unattacked alloy, and the chloride of silver, remain on the filter. This residuum is to be washed with water containing a little ammonia, which 
which dissolves the chloride of silver, while the alloy of osmium and iridium remains pure. 'This may be again calcined with the mixture of nitre and potash, to decompose it completely.

24 . Into the solution of iridium, which is of a very deep reddish-brown colour, muriate of ammonia is to be poured, and the liquid is to be evaporated to dryness, at a gentle heat. The residuum is to be then treated with alcohol very highly rectified, which takes up the excess of sal ammoniac, and occasionally a little nuriate of iron; because the alloy sumetimes contains a little of this metal. When the alcohol is no longer coloured, the ammonio-muriate of iridium remains pure. It is necessary merely to calcine it strongly in a crucible to have pure iridium. This metal, being more infusible than rhodium, can be melted only in very small quantities by the oxygen on charcoal, or hydrogen blow-pipe.

XL. Observations on Mr. Nrwton's Articles on Algebra, published in our January and February Numbers. By A CoRRESPONDENT.

\section{To Dr. Tilloch.}

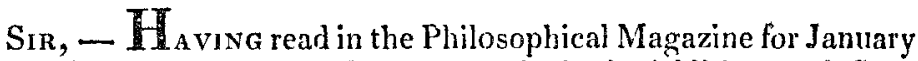
and February last, two letters on algebraic Addition and Subtraction, I beg leave to offer a few remarks on the subject.

The writer of the letters here referred to observes, that " the operations of addition should be restricted to quantities, whether like or unlike, which have like signs; and that that part of addition which consists in collecting quantities, whether like or unlike, which have unlike signs, should be classed under the rule for the subtraction of simple quantities." Thus, to find the sum $(n-m)$ of $n$ and $-m$, is, according to the observation above gnoted, called an example under the rule of subtraction. In order to judge of the propriety or impropriety of classing such an example under such a rule, we must consider whether the vature of the proposition contained in the example corresponds with the definition of the rule under which such example is placed; for it is not the manner of working the example, but the thing therein proposed to be done, that must point out the rule to which it (the example) belongs. Now as subtraction consists not in finding the sums but the differences of quantities, it is speaking quite contrary to the definition of the term (subtraction) to call that an example under subtraction, in which (example) it proposed merely to collect quantities together, be the nature of those quantities what it may. Hence the above 